\title{
Functional activity of peripheral blood eosinophils in allergen-induced late-phase airway inflammation in asthma patients
}

\author{
Simona Lavinskiene*, Kestutis Malakauskas, Jolanta Jeroch, Deimante Hoppenot and Raimundas Sakalauskas
}

\begin{abstract}
Objective: We aimed to investigate peripheral blood eosinophil chemotaxis, generation of spontaneous reactive oxygen species (ROS), and apoptosis in patients with allergic asthma after bronchial allergen challenge.

Material and methods: A total of 18 patients with allergic asthma (AA), 14 with allergic rhinitis (AR), and 10 healthy subjects (HS) underwent bronchial challenge with a specific allergen extract. Eosinophils from peripheral blood were isolated $24 \mathrm{~h}$ before as well as 7 and $24 \mathrm{~h}$ after bronchial allergen challenge. Chemotaxis, spontaneous ROS production in eosinophils, and apoptosis were analyzed by flow cytometry. Serum and induced sputum IL-5 levels were measured by ELISA; the cell count in sputum was analyzed by the May-Grünwald-Giemsa method.
\end{abstract}

Results: Before bronchial allergen challenge, peripheral blood eosinophil chemotaxis, spontaneous ROS production was enhanced and eosinophil apoptosis was reduced in the patients with AA as compared with AR patients and HS $(P<0.05)$. Meanwhile, eosinophil chemotaxis and ROS generation markedly increased in the patients with AA $7 \mathrm{~h}$ and $24 \mathrm{~h}$ after challenge compared with other groups and baseline values $(P<0.05)$. The percentage of apoptotic eosinophils in the patients with AA decreased at $7 \mathrm{~h}$ as well as $24 \mathrm{~h}$ after challenge when compared with other groups and the baseline values $(P<0.05)$. There was a significant correlation between the migrated peripheral blood eosinophil count and the sputum eosinophil count $(R s=0.89, P<0.0001)$ and the sputum IL-5 level $(R s=0.68$, $P=0.002$ ) at $24 \mathrm{~h}$ after bronchial challenge only in the patients with AA. Furthermore, the percentage of peripheral blood apoptotic eosinophils significantly correlated with eosinophil count in sputum ( $R s=-0.53, P=0.02$ ), and ROS production correlated with the serum IL-5 levels $(R s=0.71, P=0.01)$.

Conclusion: During allergen-induced late-phase airway inflammation, peripheral blood eosinophils demonstrated further alterations of their functional activity manifested by enhanced spontaneous ROS production, increased chemotaxis, and diminished apoptosis in patients with AA.

Keywords: Eosinophils, Airway inflammation, Allergic asthma, Apoptosis, Chemotaxis, ROS

\section{Introduction}

Asthma is an inflammatory disorder of the airways involving T-cells, mast cells, and eosinophils [1]. The toxic components of eosinophils are thought to be important in inducing bronchial mucosal injury and dysfunction [2]. Following airway allergen exposure, the development of airway eosinophilia is associated with increased IL-5 expression in the sputum, elevated concentrations of

\footnotetext{
* Correspondence: lavinskiene.simona@gmail.com

* Correspondence: lavinskiene.simona@gmail.com
Department of Pulmonology and Immunology, Lithuanian University of Health Sciences, Kaunas, Lithuanian
}

(c) 2015 Lavinskiene et al.; licensee BioMed Central. This is an Open Access article distributed under the terms of the Creative Commons Attribution License (http://creativecommons.org/licenses/by/4.0), which permits unrestricted use, distribution, and reproduction in any medium, provided the original work is properly credited. The Creative Commons Public Domain Dedication waiver (http://creativecommons.org/publicdomain/zero/1.0/) applies to the data made available in this article, unless otherwise stated. acity of airway cells for ex vivo generation of IL-5 [3-5]

IL-5 plays a key role in eosinophil proliferation, differentiation, maturation, migration to tissue sites and survival, as well as prevention of eosinophil apoptosis $[6,7]$. Eosinophil chemotaxis to the lungs during allergic airway inflammation represents a major part of the inflammation process [8]. Transmigration of the eosinophil through the vascular endothelium is a multistep process; rolling, tethering, firm adhesion, and transendothelial migration are regulated by the coordinated interaction between networks involving chemokine, cytokine and 
adhesion molecules $[9,10]$. Experiments with in vitro allergen as well as endobronchial allergen challenge have shown that blood and bronchoalveolar lavage eosinophils from subjects with asthma have a greater responsiveness to chemoattractants and enhanced chemotaxis $[11,12]$. During the process of allergic inflammation, eosinophils release not only toxic granule proteins but also reactive oxygen species (ROS), which are known to cause tissue damage [13]. It has been demonstrated that allergic patients have upregulated oxidative metabolism in blood eosinophils when compared with healthy subjects $[14,15]$. It leads to the observations that eosinophils isolated from allergic patients might be already activated in peripheral blood streams before they infiltrate the tissue.

In the absence of any inflammatory survival-prolonging factors, eosinophils die by apoptosis in a few days, but in inflamed airways, eosinophils survival is thought to be prolonged due to the surrounding proinflammatory factors such as IL-5, IL-3, and granulocyte-macrophage colony-stimulating factor [16,17]. There are some data about impaired peripheral blood eosinophil apoptosis in allergic patients [18], and this might contribute to greater airway eosinophilia.

There is no doubt that eosinophils are important cells which participate in allergic airway inflammation. Meanwhile, associations between eosinophil infiltration in the airways and peripheral blood eosinophil chemotaxis, ROS production, and apoptosis have not been completely elucidated yet. Therefore, the regulation of blood eosinophil activity in asthmatic patients especially after allergen challenge needs to be investigated.

We hypothesized that evaluating peripheral blood eosinophils functional activity (chemotaxis, apoptosis, and ROS production) during allergen-induced late-phase airway inflammation is important for understanding the pathogenesis of eosinophilic inflammation in the airways.

\section{Methods}

Subjects

A total of 42 nonsmoking adults (13 men and 29 women) were examined: 18 patients with intermittent or mild-tomoderate persistent allergic asthma, defined according to the GINA criteria [19], 14 patients with mild-to-moderate persistent allergic rhinitis, defined according to the ARIA criteria [20], and 10 healthy subjects who comprised the control group. The patients were recruited from the Department of Pulmonology and Immunology, Hospital of the Lithuanian University of Health Sciences, Kaunas. The study protocol was approved by the Regional Biomedical Research Ethics Committee of the Lithuanian University of Health Sciences (BE-2-23), and each participant gave his/ her informed written consent. The study was registered in the U.S. National Institutes of Health trial registry ClinicalTrials.gov with identifier NCT02214303.
Patients with allergic asthma and rhinitis had a clinical history of the disease for $\geq 1$ year, current symptoms, and positive results of skin prick test $(\geq 3 \mathrm{~mm})$ with the following allergens: Dermatophagoides pteronyssinus ( $D$. pteronyssinus), birch pollen, or mixture of 5 grasses. All the patients were not using inhaled, nasal, or oral steroids at least 1 month before visits; short-acting $\beta 2$ agonists, at least $12 \mathrm{~h}$; long-acting $\beta 2$ agonists, at least $48 \mathrm{~h}$ prior the lung function test, and antihistamines and antileukotrienes, 7 days before the skin prick test and the lung function test. None of the patients had a history of smoking. Baseline forced expiratory volume in one second $\left(\mathrm{FEV}_{1}\right)$ was more than $70 \%$ of the predicted value in all patients. All the healthy subjects were nonsmokers, without symptoms of asthma or rhinitis, with normal findings of spirometry, and all showed negative results of the skin prick test.

\section{Skin prick and lung function testing}

All the patients were screened for allergy by the skin prick test using standardized allergen extracts (Stallergenes S.A., France) for the following allergens: $D$. pteronyssinus, $D$. farinae, cat and dog dander, mixture of pollen of 5 grasses, birch pollen, mugwort, Alternaria, Aspergillus, and Cladosporium. Histamine hydrochloride $(10 \mathrm{mg} / \mathrm{mL})$ was used for a positive control. Skin testing was read $15 \mathrm{~min}$ after application. The results of the skin prick test were considered positive if the mean wheal diameter was $\geq 3 \mathrm{~mm}$ [21].

Pulmonary function was tested using a pneumotachometric spirometer "CustovitM" (Custo Med, Germany). Baseline $\mathrm{FEV}_{1}$, forced vital capacity (FVC), and $\mathrm{FEV}_{1}$ / FVC ratio were recorded as the highest of three reproducible measurements. The results were compared with the predicted values matched for age, body height, and sex according to the standard methodology [22].

\section{Measurement of airway responsiveness to methacholine}

Airway responsiveness was assessed as changes in the airway function after challenge with inhaled methacholine using a reservoir method [23]. Methacholine was nebulized into a $10-\mathrm{L}$ reservoir with a pressure nebulizer (Pari Provocation I; Pari, Stanberg, Germany). Aerolized methacholine was inhaled through a one-way valve at 5min intervals starting with $15-\mu \mathrm{g}$ methacholine dose and doubling it until a 20\% decrease in $\mathrm{FEV}_{1}$ from the baseline or the total cumulative dose of $3.87 \mathrm{mg}$ was achieved. The bronchoconstricting effect of each dose of methacholine was expressed as a percentage of decrease in $\mathrm{FEV}_{1}$ from the baseline value. The provocative dose of methacholine causing a $\geq 20 \%$ fall in $\mathrm{FEV}_{1}\left(\mathrm{PD}_{20}\right)$ was calculated from the log dose-response curve by linear interpolation of two adjacent data points. 
Peripheral blood collection and isolation of eosinophils

Peripheral blood samples for eosinophil isolation were collected into sterile vacutainers with ethylenediaminetetraacetic acid (EDTA). Polymorphonuclear leukocytes (PMNs) were isolated by high density gradient centrifugation. The whole blood was layered on Ficoll-Paque PLUS (GE Healthcare, Finland) and centrifuged at $1000 \mathrm{~g}$ for $30 \mathrm{~min}$ at room temperature. PMNs were separated by hypotonic lysis of erythrocytes and eosinophils were separated using a magnetic eosinophil isolation kit (Miltenyi Biotek, USA). Isolated eosinophils were diluted in cell culture RPMI 1640 media (Biological Industries, Israel) at a final concentration of $2 \times 10^{6} / \mathrm{mL}$. The viability of eosinophil was checked flow cytometrically using propidium iodide $(2 \mathrm{mg} / \mathrm{mL})$ and it always was $>95 \%$.

\section{Sputum induction and processing}

The subjects inhaled $10 \mathrm{~mL}$ of sterile hypertonic saline solution $(3 \%, 4 \%$, or $5 \% \mathrm{NaCl}$, Ivex Pharmaceuticals, USA) at room temperature from an ultrasonic nebulizer (DeVilbiss Health Care, USA). The duration of each inhalation was $7 \mathrm{~min}$, and it was stopped after expectoration an adequate amount of sputum. In order to detect a possible decrease in $\mathrm{FEV}_{1}$, spirometry was performed after each inhalation. Sputum was poured into a Petri dish and separated from saliva. A 4-fold volume of freshly prepared $0.1 \%$ dithiothreitol (DTT; Sigma-Aldrich) was added. The mixture was vortexed and placed on a bench rocker for $15 \mathrm{~min}$ at room temperature. Next, an equal volume of phosphate-buffered saline solution (PBS; Sigma-Aldrich) was added to DTT. The cell pellet was separated using a $40-\mu \mathrm{m}$ cell stainer (Becton Dickinson, USA). The mixture was centrifuged for $10 \mathrm{~min}$ at $4^{\circ} \mathrm{C}$; the supernatant was aspirated and stored at $-70^{\circ} \mathrm{C}$ for later analysis. The total cell counts, percentage of epithelial cells, and cell viability were investigated using a Neubauer hemocytometer (Heinz-Herenz, Germany) under a microscope (B5 Professional, Motic, China) by employing the Trypan blue exclusion method. The cytospin samples of induced sputum were prepared using a cytofuge instrument (Shandon Southern Instruments, USA).

\section{Induced sputum cell analysis}

The prepared sputum cytospins were stained by the May-Grünwald-Giemsa method for differential cell counts. Cell differentiation was determined by counting approximately 400 cells in random fields of view under a light microscope, excluding squamous epithelial cells. The cells were identified by standard morphological criteria, nuclear morphology, and cytoplasmic granulation. Cell counts were expressed as percentages of total cells and absolute values $\left(10^{6} / \mathrm{L}\right)$.

\section{Peripheral blood eosinophil chemotaxis, apoptosis and ROS production assay}

\section{Chemotaxis in vitro}

Eosinophil chemotaxis in vitro was performed in a 10well cell transmigration chamber (Neuro Probe, USA). The lower and upper wells of chamber were isolated by a polyvinylpyrrolidone (PVP)-treated polycarbonate tracketch membrane, containing $2 \times 10^{6} 3 \mu \mathrm{m} / \mathrm{mm}^{2}$ pores (Neuro Probe, USA). The lower wells were pre-filled with isotonic Percoll (GE Healthcare, Finland) and eotaxin, a chemotactic factor, at different concentrations (10, 100, or $1000 \mathrm{ng} / \mathrm{mL})$. RPMI 1640 was used as a negative control. The upper wells were filled with eosinophil culture suspension $\left(1 \times 10^{3} / \mathrm{mL}\right)$ and incubated for $2 \mathrm{~h}\left(37^{\circ} \mathrm{C}, 5 \% \mathrm{CO}_{2}\right)$.

After the incubation, the suspensions of upper and lower wells were resuspended in tubes for flow cytometry. Nonmigrated eosinophils remained in the upper wells. The migration rate was calculated from the total number of eosinophils harvested from the lower well and expressed as percentage of the total input of eosinophils into the upper well.

The number of migrated eosinophils was calculated by flow cytometry using Liquid Counting Beads (BD Biosciences, USA) according to the manufacturer's recommendations. The amount of migrated eosinophils was expressed in percentages.

\section{Apoptosis}

Isolated eosinophils were resuspended in the annexinbinding buffer ( $\mathrm{pH}$ 7.4) containing $50 \mathrm{mM}$ HEPES, $700 \mathrm{mM} \mathrm{NaCl}, 12.5 \mathrm{mM} \mathrm{CaCl} 2$ (Invitrogen, USA) and incubated with fluorescein isothiocyanate-labeled (FITC)annexin V (Invitrogen, USA) and propidium iodide (PI) for $15 \mathrm{~min}$ at room temperature in the dark. After the incubation, apoptosis was analyzed by flow cytometry using the CellQuest software (BD Biosciences, USA). Apoptotic cells were quantified as the percentage of the total population that was positive for FITC, but negative for PI. Necrotic cells were positive for PI.

\section{Analysis of ROS production}

Spontaneous ROS production in peripheral blood eosinophils was performed in sterile 96-well microplates (Falcon, BD, USA). For the detection of generated ROS, dihydrorhodamine-123 (DHR-123, $750 \mathrm{ng} / \mathrm{mL}$ final, Invitrogen, USA), a nonfluorescent dye, was added. DHR-123, interacting with intracellular ROS, is oxidized to the green-fluorescent rhodamine-123. The plates were filled with eosinophil cultures and incubated for $45 \mathrm{~min}$ $\left(37^{\circ} \mathrm{C}, 5 \% \mathrm{CO}_{2}\right)$. The relative amount of generated ROS was measured flow cytometrically by determination of mean green fluorescence intensity in the eosinophil population. 


\section{Detection of cytokine in serum and induced sputum supernatant}

The serum and sputum IL-5 levels were measured by an enzyme-linked immunosorbent assay (ELISA) according to the manufacturer's instructions (Abcam, USA). The minimum detectable concentration was $5 \mathrm{pg} / \mathrm{mL}$.

The peripheral blood cell analysis was performed on an automated hematology analyzer (Sysmex XE-5000, Japan).

\section{Statistical analysis}

Statistical analysis was performed by using the Statistical Package for Social Sciences, version 17.0 for Windows (SPSS 17.0). The normality assumption of data was verified with the Kolmogorov-Smirnov test. The data were expressed as a median and a range. The results of methacholine $\mathrm{PD}_{20}$ measurements are expressed as a geometric mean. $\mathrm{PD}_{20}$ values were log-transformed for analysis to fit a normal distribution.

Due to a skewed distribution of the variable, nonparametric tests were applied. The Kruskal-Wallis test was used to evaluate differences between the groups of patients and the control group. Differences between 2 independent groups were determined by the MannWhitney $U$ test. Differences among 3 and more paired samples were evaluated by the Friedman test. Differences between 2 dependent samples were evaluated by the Wilcoxon test. The Spearmen rank test was used to assess relationships between measurements. Statistical significance was assumed at a $P$ value of $<0.05$.

\section{Results}

\section{Characteristics of studied subjects}

A total of 42 nonsmoking adults (17 men and 25 women; mean age $31 \pm 9$ years) were examined: 18 patients with intermittent or mild-to-moderate persistent allergic asthma, 14 patients with mild-to-moderate persistent allergic rhinitis, and 10 healthy subjects who comprised the control group. There were no significant age and gender differences comparing the groups. Twentyone patients were sensitized to $D$. pteronyssinus; 5 patients, to birch pollen; and 6 patients, to a mixture of pollen of 5 grasses. The mean wheal diameter induced by an allergen was similar in both groups of patients. The demographic and clinical data of the study subjects are presented in Table 1. There were no significant difference in the baseline $\mathrm{FEV}_{1}$ (\% of predicted) the comparing all groups. A provocative dose of methacholine causing a 20\% decrease in $\mathrm{FEV}_{1}$ $\left(\mathrm{PD}_{20}\right)$ was documented in 18 patients with allergic asthma and 1 patient with allergic rhinitis.

\section{Eosinophil composition of peripheral blood and induced sputum}

The eosinophil count in the peripheral blood $24 \mathrm{~h}$ before bronchial allergen challenge was significantly higher in the patients with allergic asthma compared with the patients with allergic rhinitis and healthy subjects $\left(0.32 \times 10^{9} / \mathrm{L}\right.$ [range, $\left.0.09-0.65\right]$ vs. $0.16 \times 10^{9} / \mathrm{L}[0.04-$ $0.88]$ and $0.13 \times 10^{9} / \mathrm{L}$ [0.04-0.94], $\left.P<0.05\right)$. At 24 hours after bronchial challenge, the peripheral blood eosinophil count was significantly increased in the patients with allergic asthma compared with the baseline values and the healthy subjects (Figure 1A). The increased peripheral blood eosinophil count also was recorded $24 \mathrm{~h}$ after bronchial challenge in the patients with allergic rhinitis compared with the baseline values $\left(0.22 \times 10^{9} / \mathrm{L}\right.$ [range, $0.04-1.19$ ] vs. $0.16 \times 10^{9} / \mathrm{L}$ [range, $0.04-0.88$ ] $P<0.05)$. Meanwhile, at the baseline as well as $7 \mathrm{~h}$ and $24 \mathrm{~h}$ after bronchial challenge, the total eosinophil count in the sputum was significantly higher in the patients with allergic asthma than those with allergic rhinitis and the healthy subjects $(P<0.05)$ (Figure 1B). At the baseline as well as $7 \mathrm{~h}$ and $24 \mathrm{~h}$ after bronchial challenge, the patients with allergic rhinitis showed a significantly greater eosinophil count in the sputum than the healthy subjects $(P<0.05)$. Bronchial allergen challenge had no impact on eosinophil count in healthy subjects.

Table 1 Demographic and clinical characteristics of study subjects

\begin{tabular}{|c|c|c|c|}
\hline Characteristics & $\begin{array}{l}\text { Patients with allergic asthma } \\
\mathrm{N}=18\end{array}$ & $\begin{array}{l}\text { Patients with allergic rhinitis } \\
\mathrm{N}=14\end{array}$ & $\begin{array}{l}\text { Healthy subjects } \\
\mathrm{N}=10\end{array}$ \\
\hline Age (years), median (range) & $31(21-50)$ & $30(18-49)$ & $28(22-45)$ \\
\hline Sex (male/female), n & $10 / 8$ & $4 / 10$ & $3 / 7$ \\
\hline Wheal diameter induced by allergen (mm), median (range) & $6.2(4-11)$ & $7.8 \pm 1.8(4-13)$ & 0 \\
\hline Sensitization to D. pteronyssinus/birch/5 grass mixture allergen, $\mathrm{n}$ & $13 / 3 / 2$ & $9 / 3 / 2$ & 0 \\
\hline $\mathrm{PD}_{20}$ (mg), geometric mean (range) & $0.38(0.25-0.54)$ & $0.52^{*}$ & $0 / 0 / 0$ \\
\hline $\mathrm{FEV}_{1}(\%$ of predicted), mean $\pm \mathrm{SD}$ & $98 \pm 15$ & $105 \pm 10$ & $102 \pm 11$ \\
\hline
\end{tabular}

${ }^{*} \mathrm{~N}=1$ because methacholine challenge provoked bronchoconstriction only to one allergic rhinitis patient.

$\mathrm{PD}_{20}$ - a provocative dose of methacholine causing a $20 \%$ decrease in $\mathrm{FEV}_{1}$.

$\mathrm{FEV}_{1}$ - forced expiratory volume in one second. 


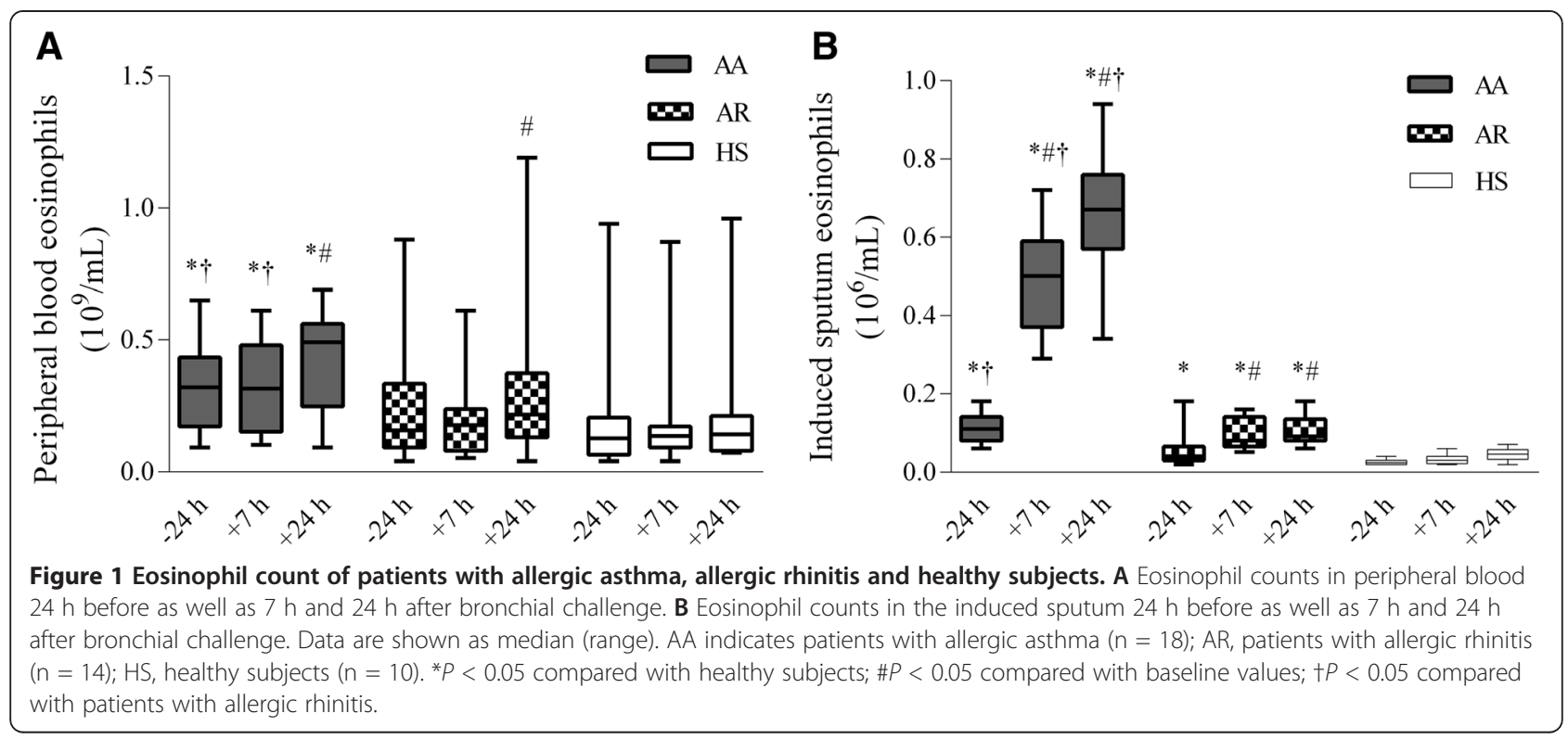

Functional activity of peripheral blood eosinophils Peripheral blood eosinophil chemotaxis in vitro

Eotaxin at different concentrations (10, 100, and $1000 \mathrm{ng} / \mathrm{mL}$ ) had an impact on peripheral blood eosinophil chemotaxis in all the studied groups, but the highest concentration had the greatest effect. At the baseline, peripheral blood eosinophil chemotaxis after the stimulation with $1000 \mathrm{ng} / \mathrm{mL}$ of eotaxin was higher in the patients with allergic asthma compared with those with allergic rhinitis and the healthy subjects $(P<0.05)$. At $7 \mathrm{~h}$ and $24 \mathrm{~h}$ after bronchial challenge, eosinophil chemotaxis was significantly enhanced in the patients with allergic asthma compared with the baseline values, and it was greater than in the patients with allergic rhinitis and the healthy subjects (Figure 2). Meanwhile, bronchial allergen challenge had no significant effect on eosinophil chemotaxis in the peripheral blood of healthy subjects.

\section{ROS in peripheral blood eosinophils}

Before bronchial allergen challenge, spontaneous ROS production in peripheral blood eosinophils was significantly greater in the patients with allergic asthma compared than those with allergic rhinitis and the healthy subjects $(P<0.05)$. At $7 \mathrm{~h}$ and $24 \mathrm{~h}$ after bronchial challenge, ROS generation was significantly greater in the patients with allergic asthma compared with other groups and the baseline values (Figure 3). Bronchial allergen challenge had no impact on ROS production in eosinophils isolated from the healthy subjects.

\section{Apoptosis of peripheral blood eosinophils}

Before bronchial allergen challenge, the patients with allergic asthma had a significantly lower percentage of apoptotic peripheral blood eosinophils than those with allergic rhinitis and the healthy subjects $(P<0.05)$ (Figure 4$)$. Furthermore, $7 \mathrm{~h}$ and $24 \mathrm{~h}$ after bronchial challenge, a significantly lower percentage of apoptotic peripheral blood eosinophils was recorded in the asthma patents' group when compared with other groups and the baseline values $(P<0.05)$.

\section{IL-5 Levels in induced sputum and serum}

There was a significant increase in the induced sputum IL-5 levels in the patients with allergic asthma and those with allergic rhinitis compared with the healthy subjects at $24 \mathrm{~h}$ before bronchial challenge (Figure 5A). At $7 \mathrm{~h}$

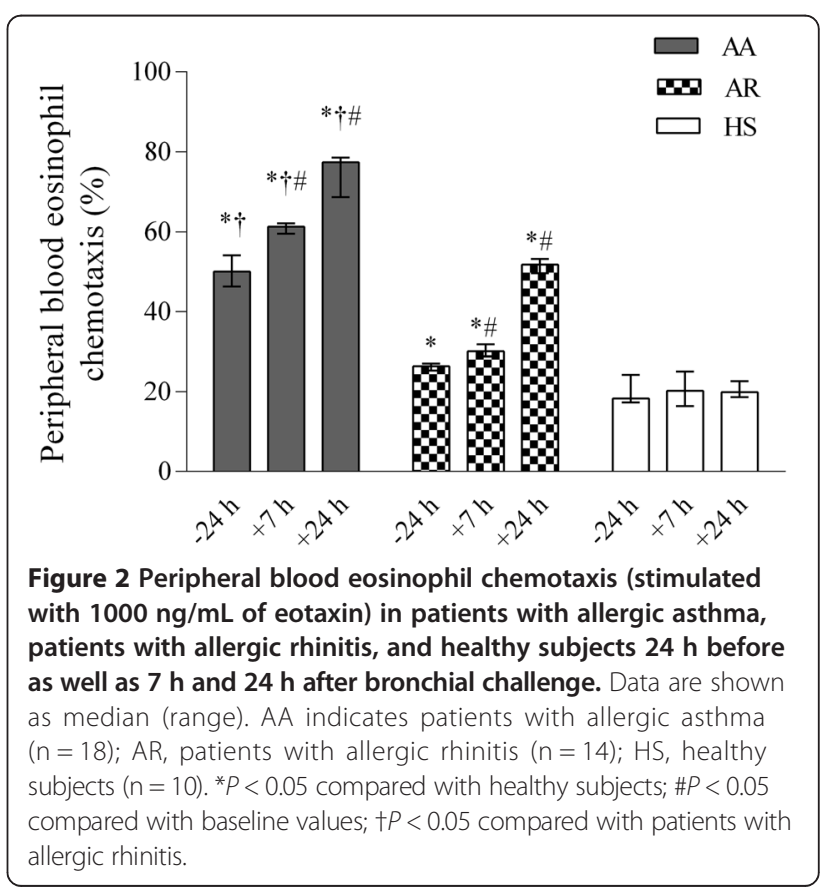




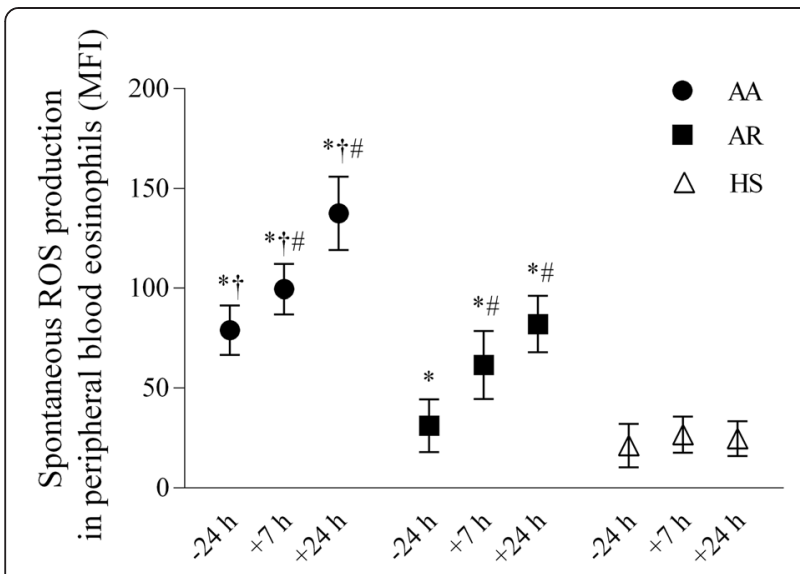

Figure 3 Production of reactive oxygen species in peripheral blood eosinophils of patients with allergic asthma, patients with allergic rhinitis, and healthy subjects $24 \mathrm{~h}$ before as well as $\mathbf{7 ~} \mathrm{h}$ and $\mathbf{2 4} \mathrm{h}$ after bronchial challenge. Data are shown as median (range). AA indicates patients with allergic asthma $(n=18)$; $A R$, patients with allergic rhinitis $(n=14) ; H S$, healthy subjects $(n=10)$; $\mathrm{MFI}$, mean fluorescence intensity. ${ }^{*} P<0.05$ compared with healthy subjects; $\# P<0.05$ compared with baseline values; $+P<0.05$ compared with patients with allergic rhinitis.

and $24 \mathrm{~h}$ after bronchial challenge, the induced sputum IL-5 levels increased significantly in the patients with allergic asthma and those with allergic rhinitis compared with the healthy subjects. Moreover, the sputum IL-5 levels at $7 \mathrm{~h}$ and $24 \mathrm{~h}$ after bronchial challenge were significantly higher in the patients with allergic asthma than those with allergic rhinitis. The same tendency was observed while analyzing serum IL-5 levels (Figure 5B). However, in patients with allergic rhinitis, there was no significant difference in the serum IL-5 levels comparing

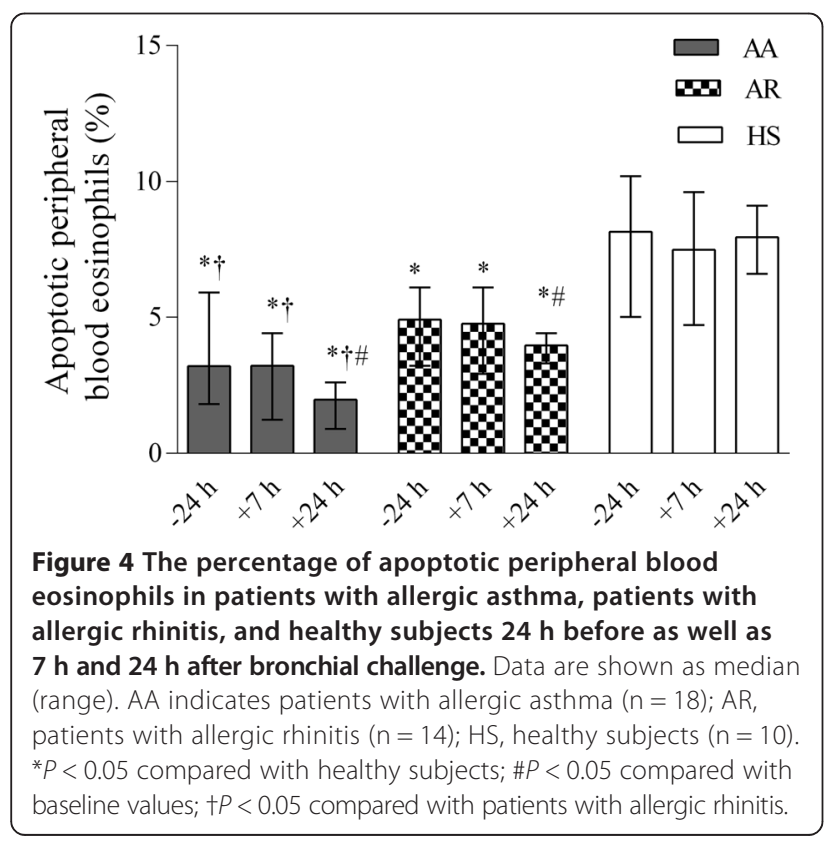

the baseline values with those recorded $7 \mathrm{~h}$ after bronchial challenge. Bronchial challenge had no impact on the IL-5 levels in the sputum and serum of healthy subjects.

\section{Correlations}

Significant correlations were found only in the patients with allergic asthma at $24 \mathrm{~h}$ after bronchial allergen challenge. The migrated peripheral blood eosinophil count significantly correlated with the eosinophil count in the sputum $(R \mathrm{~s}=0.89, P<0.0001$; Figure 6A). Moreover, there was a significant correlation between the percentage of apoptotic peripheral blood eosinophils and eosinophil count in sputum ( $R \mathrm{~s}=-0.53, P=0.02$; Figure $6 \mathrm{~B})$. The migrated peripheral blood eosinophil count significantly correlated with sputum IL-5 levels $(R \mathrm{~s}=0.68, P=0.002$; Figure $6 \mathrm{C}$ ), and ROS production in peripheral blood eosinophils significantly correlated with the serum IL-5 levels $(R \mathrm{~s}=0.71, P=0.01$; Figure 6D).

\section{Discussion}

This study has demonstrated that peripheral blood eosinophil chemotaxis, spontaneous ROS production, and eosinophil apoptosis are altered in patients with allergic asthma during allergen-induced late-phase airway inflammation. The increased sputum eosinophil count and enhanced levels of IL-5 significantly correlated with the impaired functional activity of peripheral blood eosinophils.

It is known that eosinophils are recruited to sites of inflammation by released chemotactic agents. Eotaxin, a CC chemokine, is one of the strongest stimulator of eosinophil chemotaxis [24]. It also induces the release of various mediators from eosinophils and is known to play an integral role in the development of eosinophilic inflammation [25]. Therefore, in order to investigate chemotaxis in vitro, peripheral blood eosinophils were stimulated with different concentrations $(10,100$, and $1000 \mathrm{ng} / \mathrm{mL}$ ) of eotaxin. Our results showed that before bronchial allergen challenge, peripheral blood eosinophil chemotaxis stimulated with the highest eotaxin concentration was greatest in the patients with allergic asthma as compared with other groups. These data suggest that eosinophils in the peripheral blood of individuals with allergic asthma are already primed and more sensitive to a chemokine.

Experiments with in vivo injection of eotaxin into the skin of mice and rhesus monkeys showed local accumulation of eosinophils, and the kinetics of allergen-induced production of eotaxin is paralleled by eosinophil accumulation in a guinea-pig model of allergic airways [25,26].

We found that $7 \mathrm{~h}$ and $24 \mathrm{~h}$ after bronchial allergen challenge, eosinophil chemotaxis was significantly greater in the patients with allergic asthma than other groups and also compared with the baseline values. This shows that not only allergen challenge stimulates the functional 

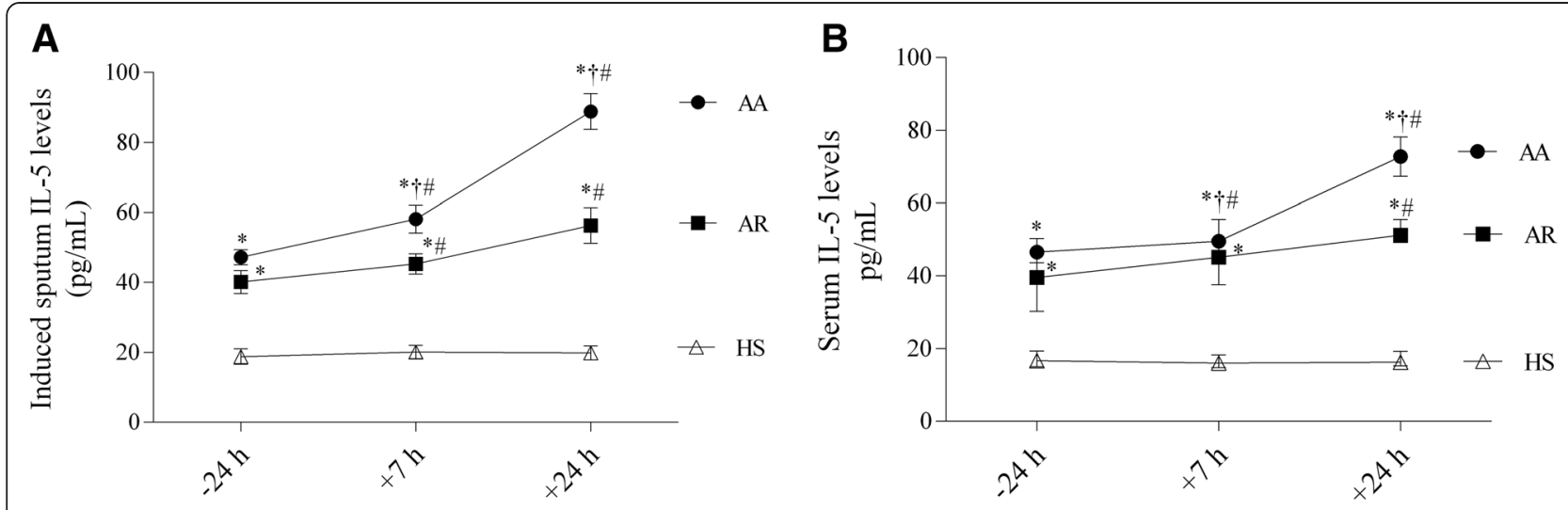

Figure 5 IL-5 levels of patients with allergic asthma, patients with allergic rhinitis, and healthy subjects. A IL-5 levels in the induced sputum $24 \mathrm{~h}$ before as well as $7 \mathrm{~h}$ and $24 \mathrm{~h}$ after bronchial allergen challenge. B IL-5 levels in serum $24 \mathrm{~h}$ before as well as $7 \mathrm{~h}$ and $24 \mathrm{~h}$ after bronchial allergen challenge. Data are shown as median (range). AA indicates patients with allergic asthma ( $n=18) ; A R$, patients with allergic rhinitis $(n=14)$; HS, healthy subjects $(n=10)$. ${ }^{*} P<0.05$ compared with healthy subjects; $\# P<0.05$ compared with baseline values; $+P<0.05$ compared with patients with allergic rhinitis.

activity of eosinophils, but response to eotaxin confirms the undeniable importance of this chemokine. Moreover, at $24 \mathrm{~h}$ after bronchial challenge, the increased eosinophil count in the sputum significantly correlated with the increased migrated eosinophil count in the peripheral blood of asthmatic patients. That can reflect the hallmark characteristic of allergic asthma by infiltration of eosinophils to the airway.

The inflammatory cells recruited to the asthmatic airways are exceptionally capable of producing ROS, resulting in abnormal physiologic function of DNA, proteins, and lipids that clinically can augment bronchial hyperresponsiveness and inflammation [27]. However due to the possibility that eosinophils can be already activated in periphery, we examined spontaneous ROS production in peripheral blood eosinophils.

Our study showed that spontaneous ROS production in peripheral blood eosinophils was significantly greater in the patients with allergic asthma than those with allergic rhinitis and the healthy subjects. Moreover, at $7 \mathrm{~h}$ and $24 \mathrm{~h}$ after bronchial allergen challenge, ROS generation in peripheral blood eosinophils was significantly greater in the patients with allergic asthma compared with the baseline values and other groups.

The upregulation of ROS production by blood eosinophils in allergic patients has been previously documented in several studies $[14,28]$, and the results of these studies as well as our date suggest that eosinophils from allergic asthma patients may might be already activated in the peripheral blood stream before they infiltrate the tissues and the inhalation of aggravating compounds such as allergens can promote stronger activation of these cells.

Moreover, it was demonstrated that a low concentration of IL-5 enhanced chemokine-primed ROS production by eosinophils [14]. Consequently, we evaluated the levels of serum IL-5 and looked for a relationship with generated ROS in peripheral blood eosinophils. We found elevated serum IL-5 levels, especially $24 \mathrm{~h}$ after bronchial challenge, in the patients with allergic asthma compared with the baseline values and other groups. Moreover, a significant correlation was observed only $24 \mathrm{~h}$ after bronchial challenge and only in the patients with allergic asthma. The increased serum IL-5 levels correlated with the enhanced ROS production in peripheral blood eosinophils $(P<0.05)$. These findings suggest that enhanced ROS generation can activate a number of redox-sensitive signaling cascades, stimulate productioninteraction of proinflammatory cytokines, and promote inflammation [29].

As it has been reported that IL-5 can enhance eosinophil migration by the upregulation of adhesion molecules on eosinophils [30], we analyzed sputum IL-5 levels and investigated the possible relationship to peripheral blood eosinophil chemotaxis. Thus, we determined a significant increase in sputum IL-5 levels in the patients with allergic asthma, and it correlated with the migrated peripheral blood eosinophil count in allergen-induced late-phase airway inflammation in asthma patients.

The accumulation of eosinophils in the asthmatic lungs is a complex process, which involves their maturation in and release from the bone marrow, adhesion and transmigration through the post-capillary endothelium, and then their chemotaxis to and activation/degranulation at inflammatory foci $[9,31]$. In the circulation and tissues, eosinophils are programmed to undergo apoptosis in the absence of viability-enhancing stimuli [31]. A defect in apoptosis might contribute to chronic tissue eosinophilia associated with asthma. Therefore, we aimed at evaluating peripheral blood eosinophil apoptosis during allergen-induced late-phase inflammation. Before bronchial challenge, the percentage of 


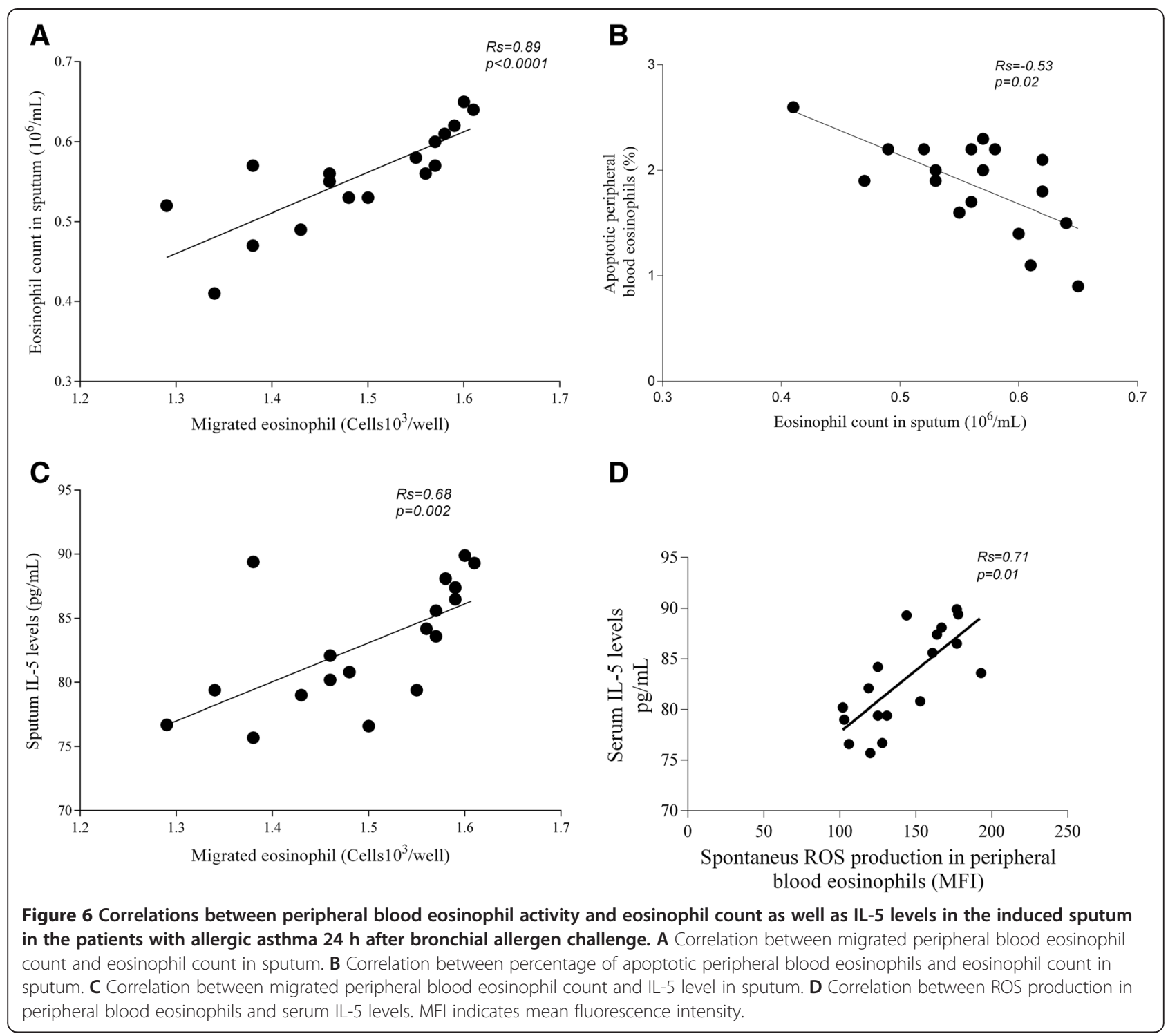

apoptotic peripheral blood eosinophils in the patients with allergic asthma was significantly lower compared with the patients with allergic rhinitis and the healthy subjects. Apoptosis of peripheral blood eosinophils in the patients with allergic asthma was more delayed $7 \mathrm{~h}$ and $24 \mathrm{~h}$ after bronchial challenge compared with the baseline and other groups. The same tendency was reported by Evans et al., who showed that in asthmatic patients demonstrating a late response, the survival of peripheral blood eosinophils is prolonged after the whole lung allergen challenge [32]. Moreover, Druilhe et al. and Vignola et al. demonstrated that asthmatic patients had greater numbers of eosinophils in the bronchial biopsy than healthy individuals [33,34]. All the above-mentioned results and findings of our study show that eosinophil survival through the inhibition of apoptosis can increase airway eosinophilia.
Finally, we evaluated relationships between eosinophil counts in the sputum and eosinophil viability after bronchi al allergen challenge, which could represent a link between eosinophilic influx to the airways possibly caused by delayed peripheral blood eosinophil apoptosis in allergen-induced late-phase airway inflammation.

Significant correlations were observed only $24 \mathrm{~h}$ after bronchial challenge and only in the patients with allergic asthma. The lower percentage of peripheral blood eosinophils was negatively correlated with the increased eosinophil count in the sputum. It might be that diminished apoptotic potential represents a mechanism that promotes resolution of eosinophilic inflammation in asthma.

In conclusion, this study has shown that allergic asthma patients demonstrates enhanced spontaneous ROS production, increased chemotaxis, and diminished 
apoptosis of peripheral blood eosinophils, and these alterations are more pronounced during allergen-induced late-phase airway inflammation.

\section{Competing interests}

The authors declare that they have no competing interests.

\section{Authors' contributions}

$\mathrm{SL}$ carried out the main experiments of this work and prepared the manuscript. KM participated in the preparation and revision of the manuscript. JJ participated in the designing the experiments. DH perforemed bronchial allergen challenge and clinical examination of all participants. RS was the leader of team. All authors have read and approved the final manuscript.

\section{Acknowledgments}

The study supported by the Researche Council of Lithuania (project number LIG-08/2012).

Received: 24 September 2014 Accepted: 27 February 2015

Published online: 29 March 2015

\section{References}

1. Spina D, Page CP. Asthma - a need for a rethink? Trends Pharmacol Sci. 2002;23(7):311-5.

2. Lintomen L, Franchi G, Nowill A, Condino-Neto A, de Nucci G, Zanesco A, et al. Human eosinophil adhesion and degranulation stimulated with eotaxin and RANTES in vitro: lack of interaction with nitric oxide. BMC Pulm Med. 2008:8:13.

3. Jarjour NN, Calhoun WJ, Kelly EA, Gleich GJ, Schwartz LB, Busse WW. The immediate and late allergic response to segmental bronchopulmonary provocation in asthma. Am J Respir Crit Care Med. 1997;155(5):1515-21.

4. Kotsimbos AT, Hamid Q. IL-5 and IL-5 receptor in asthma. Mem Inst Oswaldo Cruz. 1997;92 Suppl 2:75-91.

5. Liu LY, Sedgwick JB, Bates ME, Vrtis RF, Gern JE, Kita H, et al. Decreased expression of membrane IL-5 receptor alpha on human eosinophils: I. Loss of membrane IL-5 receptor alpha on airway eosinophils and increased soluble IL-5 receptor alpha in the airway after allergen challenge. J Immunol. 2002;169(11):6452-8.

6. Rosenberg HF, Phipps S, Foster PS. Eosinophil trafficking in allergy and asthma. J Allergy Clin Immunol. 2007;119(6):1303-10. quiz 11-2.

7. Garcia G, Taille C, Laveneziana P, Bourdin A, Chanez P, Humbert M. Antiinterleukin-5 therapy in severe asthma. Eur Respir Rev. 2013;22(129):251-7.

8. Barthel SR, Jarjour NN, Mosher DF, Johansson MW. Dissection of the hyperadhesive phenotype of airway eosinophils in asthma. Am J Respir Cell Mol Biol. 2006;35(3):378-86.

9. Wardlaw AJ. Molecular basis for selective eosinophil trafficking in asthma: a multistep paradigm. J Allergy Clin Immunol. 1999;104(5):917-26.

10. Wardlaw AJ. The role of adhesion in eosinophil function. Chem Immunol. 2000;78:93-111.

11. Plotz SG, Traidl-Hoffmann C, Feussner I, Kasche A, Feser A, Ring J, et al. Chemotaxis and activation of human peripheral blood eosinophils induced by pollen-associated lipid mediators. J Allergy Clin Immunol. 2004;113(6):1152-60.

12. Teran LM, Noso N, Carroll M, Davies DE, Holgate S, Schroder JM. Eosinophil recruitment following allergen challenge is associated with the release of the chemokine RANTES into asthmatic airways. J Immunol. 1996;157(4):1806-12.

13. Barnes PJ. Reactive oxygen species and airway inflammation. Free Radic Biol Med. 1990;9(3):235-43.

14. Sannohe S, Adachi T, Hamada K, Honda K, Yamada Y, Saito N, et al. Upregulated response to chemokines in oxidative metabolism of eosinophils in asthma and allergic rhinitis. Eur Respir J. 2003;21(6):925-31.

15. Sedgwick JB, Geiger KM, Busse WW. Superoxide generation by hypodense eosinophils from patients with asthma. Am Rev Respir Dis. 1990;142(1):120-5.

16. Walsh GM. Mechanisms of human eosinophil survival and apoptosis. Clin Exp Allergy. 1997;27(5):482-7.

17. IImarinen $\mathrm{P}$, Kankaanranta $\mathrm{H}$. Eosinophil apoptosis as a therapeutic target in allergic asthma. Basic Clin Pharmacol Toxicol. 2014;114(1):109-17.

18. Kankaanranta H, Lindsay MA, Giembycz MA, Zhang X, Moilanen E, Barnes PJ. Delayed eosinophil apoptosis in asthma. J Allergy Clin Immunol. 2000;106(1 Pt 1):77-83

19. Global initiative for asthma (GINA). Global strategy for asthma management and prevention: NHLBI/WHO workshop report. Bethesda: National Institutes of Health, National Heart, Lung and Blood Institute; 2002. Revised 2012. Available from: http://www.ginasthma.org/.

20. Bousquet J, Khaltaev N, Cruz AA, Denburg J, Fokkens WJ, Togias A, et al. Allergic Rhinitis and its Impact on Asthma (ARIA) 2008 update (in collaboration with the World Health Organization, GA(2)LEN and AllerGen). Allergy. 2008;63 Suppl 86:8-160.

21. Bousquet J, Heinzerling L, Bachert C, Papadopoulos NG, Bousquet PJ, Burney $P G$, et al. Practical guide to skin prick tests in allergy to aeroallergens. Allergy. 2012;67(1):18-24.

22. Pellegrino R, Viegi G, Brusasco V, Crapo RO, Burgos F, Casaburi R, et al. Interpretative strategies for lung function tests. Eur Respir J. 2005;26(5):948-68.

23. Baur $X$, Huber $H$, Degens $P O$, Allmers $H$, Ammon J. Relation between occupational asthma case history, bronchial methacholine challenge, and specific challenge test in patients with suspected occupational asthma. Am J Ind Med. 1998;33(2):114-22.

24. Pease JE, Williams TJ. Eotaxin and asthma. Curr Opin Pharmacol. 2001;1(3):248-53.

25. Kampen GT, Stafford S, Adachi T, Jinquan T, Quan S, Grant JA, et al. Eotaxin induces degranulation and chemotaxis of eosinophils through the activation of ERK2 and p38 mitogen-activated protein kinases. Blood. 2000;95(6):1911-7.

26. Collins PD, Marleau S, Griffiths-Johnson DA, Jose PJ, Williams TJ. Cooperation between interleukin- 5 and the chemokine eotaxin to induce eosinophil accumulation in vivo. J Exp Med. 1995;182(4):1169-74.

27. Jiang L, Diaz PT, Best TM, Stimpfl JN, He F, Zuo L. Molecular characterization of redox mechanisms in allergic asthma. Ann Allergy Asthma Immunol. 2014;113(2):137-42.

28. Shult PA, Graziano FM, Busse WW. Enhanced eosinophil luminol-dependent chemiluminescence in allergic rhinitis. J Allergy Clin Immunol. 1986;77(5):702-8.

29. Wood LG, Gibson PG, Garg ML. Biomarkers of lipid peroxidation, airway inflammation and asthma. Eur Respir J. 2003;21(1):177-86.

30. Giembycz MA, Lindsay MA. Pharmacology of the eosinophil. Pharmacol Rev. 1999:51(2):213-340.

31. Walsh GM. Eosinophil apoptosis: mechanisms and clinical relevance in asthmatic and allergic inflammation. Br J Haematol. 2000;111(1):61-7.

32. Evans DJ, Lindsay MA, O'Connor BJ, Barnes PJ. Priming of circulating human eosinophils following late response to allergen challenge. Eur Respir J. 1996;9(4):703-8.

33. Druilhe A, Wallaert B, Tsicopoulos A, Silva JR L e, Tillie-Leblond I, Tonnel AB, et al, Apoptosis, proliferation, and expression of $\mathrm{Bcl}-2$, Fas, and Fas ligand in bronchial biopsies from asthmatics. Am J Respir Cell Mol Biol. 1998;19(5):747-57.

34. Vignola AM, Chanez P, Chiappara G, Siena L, Merendino A, Reina C, et al. Evaluation of apoptosis of eosinophils, macrophages, and T lymphocytes in mucosal biopsy specimens of patients with asthma and chronic bronchitis. J Allergy Clin Immunol. 1999;103(4):563-73.

\section{Submit your next manuscript to BioMed Central and take full advantage of:}

- Convenient online submission

- Thorough peer review

- No space constraints or color figure charges

- Immediate publication on acceptance

- Inclusion in PubMed, CAS, Scopus and Google Scholar

- Research which is freely available for redistribution 